\title{
The efficiency of the heat pump water heater, during DHW tapping cycle
}

\author{
Arkadiusz Gużda ${ }^{1, *}$, and Norbert Szmolke ${ }^{1}$ \\ ${ }^{1}$ Opole University of Technology, Department of Environmental Engineering, 76 Prószkowska Street, 45-758 Opole, Poland
}

\begin{abstract}
This paper discusses one of the most effective systems for domestic hot water (DHW) production based on air-source heat pump with an integrated tank. The operating principle of the heat pump is described in detail. Moreover, there is an account of experimental set-up and results of the measurements. In the experimental part, measurements were conducted with the aim of determining the energy parameters and measures of the economic efficiency related to the presented solution. The measurements that were conducted are based on the tapping cycle that is similar to the recommended one in EN-16147 standard. The efficiency of the air source heat pump during the duration of the experiment was 2.43. In the end of paper, authors conducted a simplified ecological analysis in order to determine the influence of operation of air-source heat pump with integrated tank on the environment. Moreover the compression with the different source of energy (gas boiler with closed combustion chamber and boiler fired by the coal) was conducted. The heat pump is the ecological friendly source of the energy.
\end{abstract}

\section{Introduction}

Renewable energy sources are becoming more common as a result of the increasing social awareness of the issues related to the conservation of the environment. The application of renewable sources also brings about considerable ecological and economic benefits.

It is estimated that the housing sector, regardless of the location of a country on the world map, is responsible for the use of 19 do $50 \%$ of total energy that is required for the existence of households [1]. The use of energy needed for production of domestic hot water forms a considerable proportion in the overall energy balance; it is equal to $18 \%$ in the USA [2], 20\% in Brazil [3], 25\% in the UK [4], 26\% in Spain [5] and 30\% in Australia [6].

Such a huge relative portion in the energy use in the housing sector leads to continuous attempts aimed at increasing the energy efficiency of equipment and heating systems, whose role is concerned with heating households and production of domestic hot water. One of the most effective ways of increasing the energy efficiency of heating installations is associated with the use of heat pumps.

Heat pumps are capable of converting energy derived from renewable sources to useful energy, which is further applied to meet the thermal demand of a building and its occupants. A system comprising a heat pump consists of a lower heat source, heat pump unit and a higher heat source, which is formed by the system applied for distribution of heating or cooling inside the building.
The operating principle of this equipment involves the use of heat with a lower temperature (i.e. lower heat source) with the purpose of generating heat with a greater temperature. This process does not lead to carbon dioxide emission into the atmosphere.

The potential lower sources include the use of ambient air, ground, water and a storage reservoir [7]). For the case of heat pumps, whose role is limited to the production of domestic hot water, the largest proportion of units apply atmospheric air to play the role of the lower heat source. In this case, we call them air heat pumps. The most common solutions of such heat pumps comprise an integrated hot water tank.

The considerable popularity of such pumps is attributable to the low investment required in them as well as the high value of the coefficient of performance (COP). The mean value of COP for heat pumps marketed in Europe was equal to 3.1 in 2016 [8].

Energy input is required to accompany the processes in which temperature of the system is raised. The type of driving energy: electrical, mechanical or chemical is dependent on the design of a heat pump [8].

Fig. 1 presents the theoretical circulation of the medium in a compression type heat pump operating according to pressure-enthalpy graph ( $\mathrm{p}-\mathrm{h})$.

A dissipation of the pressure $\mathrm{p}_{\mathrm{g}}$ of the liquid refrigerant occurs in the condenser until the medium obtains evaporation pressure $\mathrm{p}_{0}$ in the expansion valve (line 3-4). Heat is extracted from the lower source whose role is taken on by atmospheric air so that the phase change can occur (line 4-1). The vapor which flows from the evaporator is compressed in the

Corresponding author: arkadiusz.guzda@gmail.com 
compressor (line 1-2) until the compression pressure is obtained $\mathrm{p}_{\mathrm{g}}$; this is possible due to input of external energy. The next phase involves the release of heat in the condenser (line 2-3) and the cycle is repeated.

The operating performance of a heat pump is expressed by the formula

$$
C O P=\frac{Q}{L}=\frac{Q_{O}+L}{L}=1+\frac{Q_{O}}{L}
$$

where: Q - quantity of heat absorbed by the evaporator, $\mathrm{Q}_{0}-$ quantity of heat produced in condenser, L- work delivered to the compressor.

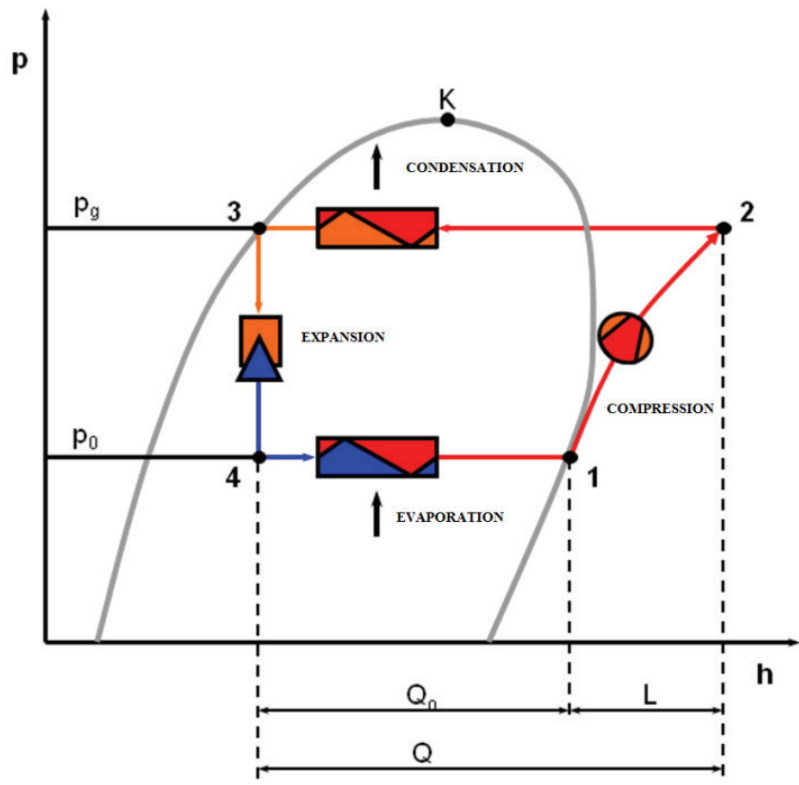

Fig. 1. Chart of the theoretical p-h cycle, where: $\mathrm{Q}_{0}$ - the quantity of heat produced in condenser, $\mathrm{Q}$ - the quantity of heat absorbed by the evaporator, $\mathrm{L}$ - work delivered to the compressor.

The thermal efficiency of air heat pumps applied for the production of domestic how water is determined by a number of factors such as: course of tapping cycle, ambient temperature, temperature of cold water entering the pump, temperature of hot water in the storage tank, etc.

In addition, heat pumps need to be able to overheat tap water above $55^{\circ} \mathrm{C}$ during a thermal disinfection cycle with the purpose of preventing the growth of legionella bacteria, as they pose health threat to humans.

The authors in [4] state that for the case of heat pumps with an integrated water tank, in some conditions water overheating would be unfeasible.

In recent years, there is a number of papers concerned with the determination of the conditions affecting the performance of heat pumps. Such reports often include a description of how heat pump performance can be increased.

In paper [9], the authors proposed a model of dynamic simulation applying three types of condenser geometries, which comprises minichannels whose COP coefficient was equal to 3.85-3.93.
Concurrently, the studies reported in [10] demonstrated the existence of a dependence between the energy efficiency of the medium, quantity of the refrigerant in the circulation, length of the condensing section and the control settings of the heat pump.

It was remarked that the adequate refrigerant charge plays an important role for the effective operation of a heat pump. Other studies suggest that the adequate selection of the capacity of the water tank forms an important design consideration.

\section{Experimental system and procedure}

\subsection{Description of the system}

The study that is presented in this paper is concerned with the determination of the relation between the efficiency of an air heat pump and the use of domestic hot water. The study was performed by application of a heat pump manufactured by a Polish company named Galmet comprising a water tank with the capacity of 200 liters; the heat pump also comprises a $2 \mathrm{~kW}$ electric heater. The system is tested at Opole University of Technology, Faculty of Mechanical Engineering $\left(50^{\circ} 41^{\prime} 00.3^{\prime \prime} \mathrm{N} 17^{\circ} 56^{\prime} 37.5^{\prime \prime} \mathrm{E}\right)$. Indoor air that is extracted from a laboratory plays the role of the lower heat source.

Table 1 contains a summary of the exploitation parameters that were measured during the operation of the heat pump.

Table 1. Summary of the measured exploitation parameters.

\begin{tabular}{|l|c|}
\hline Domestic hot water & ${ }^{\circ} \mathrm{C}$ \\
- Temperature & $\mathrm{K}$ \\
- Temperature difference & $\mathrm{dm}^{3}$ \\
- Capacity & $\mathrm{dm}^{3} / \mathrm{s}$ \\
- Volumetric flow rate & $\mathrm{kWh}$ \\
- Thermal energy (over entire & \\
$\quad$ tapping cycle) & ${ }^{\circ} \mathrm{C}$ \\
- Temperature of tank shell & \\
\hline $\begin{array}{l}\text { Refrigerant } \\
\text { - Temperature of refrigerant exiting } \\
\quad \text { the compressor }\end{array}$ & \\
- Temperature of refrigerant exiting & \\
- $\quad$ Tevaporator & \\
$\quad$ expansion valve & ${ }^{\circ} \mathrm{C}$ \\
- Temperature of refrigerant & \\
$\quad$ exiting evaporator & \\
\hline $\begin{array}{l}\text { Parameters of electrical supply } \\
\text { - Electric power }\end{array}$ & \\
- Consumption of electricity & $\mathrm{W}$ \\
- Voltage & $\mathrm{kWh}$ \\
- Current & $\mathrm{V}$ \\
\hline $\begin{array}{l}\text { Air (lower heat source) } \\
\text { - Air temperature }\end{array}$ & $\mathrm{A}$ \\
\hline - Relative humidity in air & \\
\hline
\end{tabular}




\subsection{Tapping cycles}

In accordance with the PN-EN 16147 standard [11] in force now, COP coefficient is derived on basis of a daily tapping cycle, which comprises a profile of typical water usage model determined for a typical household.

The minimum duration of such a cycle is equal to 24 hours. This cycle applies energy input required for production of DHW according to definitions in standard [11] together with the energy needed for the operation of the system [12]. The decision regarding the water tapping cycle applied in the test of a particular pump is made by the manufacturer of the equipment.

The standard defines five water tapping cycles, ranging from $\mathrm{S}-\mathrm{XXL}$. These cycles vary in terms of the minimum volume of tap water use and daily profile of its tapping cycle.

The determination of the relation between the efficiency of the heat pump and use of hot water applied a study conducted for the tapping cycle (called $\mathrm{L}$ in the standard) as it is dedicated by manufacturer for this purpose and whose course is similar to the cycle described in the standard [11]. The statement regarding the use of hot water at a level of 199.8 liters corresponding to $\mathrm{L}$ cycle is given by the manufacturer.

For the cycle applied for the measurements, the equivalent of domestic hot water (volume of water used in the system) is equal to $230 \mathrm{dm}^{3}$ per day on average. The duration of the measurements was 18 days and they lasted from March $8^{\text {th }}$ to April $5^{\text {th }}, 2017$.

The test involved three phases, whose overview is presented in Fig. 2.

Phase 1 involved the process of heating water in the tank from an initial temperature (i.e. temperature of cold water) to a temperature that was demanded for the purposes of the cycle, i.e. in the range from $45-50^{\circ} \mathrm{C}$.

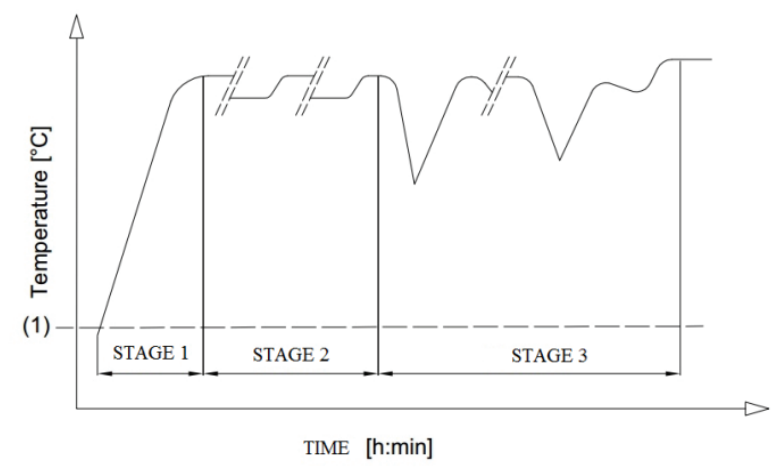

Fig. 2. Phases comprising a single tapping cycle.

Phase 2 involved the determination of energy input by the heat pump in the conditions when it is in standby mode. The final phase (phase 3) involved the determination of the energy use and coefficient of performance in the of the hot water production mode during the reference tapping cycles; throughout the duration of the cycles, various levels of water consumption were adopted.

The figure below (Fig. 3) contains the profile of the tapping cycle corresponding to the $\mathrm{L}$ cycle, as it was determined during the conducted study.

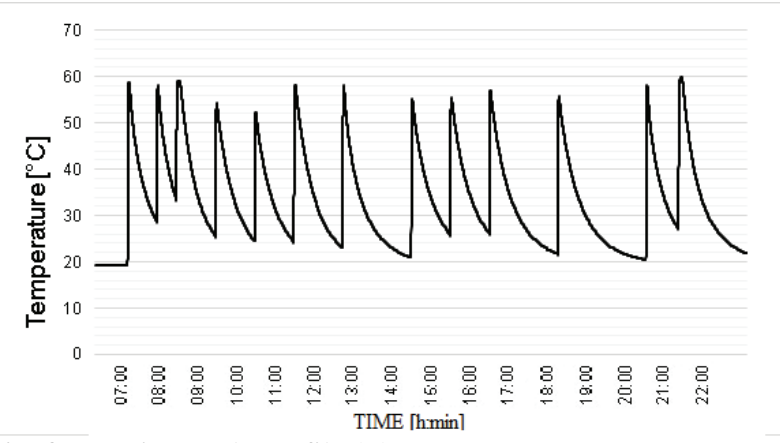

Fig. 3. Tapping cycle profile (L).

On the basis of an analysis of the above tapping profile, we can note that the greatest hot water consumption is noted for the period between 7 a.m. and 9:30 p.m. This use takes on a periodical character at constant time intervals. The longest intervals corresponding to tapping cycles are registered for the times between 12:45 p.m. and 3:30 p.m. we well as 6:30 p.m. to $8: 30$ p.m.

\section{Test results}

Fig. 4 presents a detailed temperature chart for two points: $\mathrm{T} 1$ and $\mathrm{T} 4$.

$\mathrm{T} 1$ is located in the vicinity of the hot water outlet nozzle whereas point T4 near the cold water inlet nozzle. The temperature peak which can be noted for the date March $20^{\text {th }}, 2017$ is associated with the increase of DHW temperature set-point at the outlet of the tank.

The temperature on the lower section of the tank was in the range from $19-30^{\circ} \mathrm{C}$; whereas in the top section it was in the range from $35-48^{\circ} \mathrm{C}$.

The following figure (Fig. 5) contains the chart of the compression and dissipation pressure which accompany the operation of the heat pump in the analyzed period.

The compression pressure during the operation of the heat pump was equal to 16 bar at a maximum, whereas the pressure behind the thermostatic expansion valve (TEV) was around 2.5 bar.

The subsequent chart in Fig.6 presents the values of the temperatures measured after the basic components of the heat pump, i.e. evaporator, expansion valve, before and after the condenser.

We can note that the temperature after the compressor (and before the condenser) increased to nearly $68^{\circ} \mathrm{C}$, whereas the temperature of the refrigerant behind the evaporator was in the range $16-24^{\circ} \mathrm{C}$. 


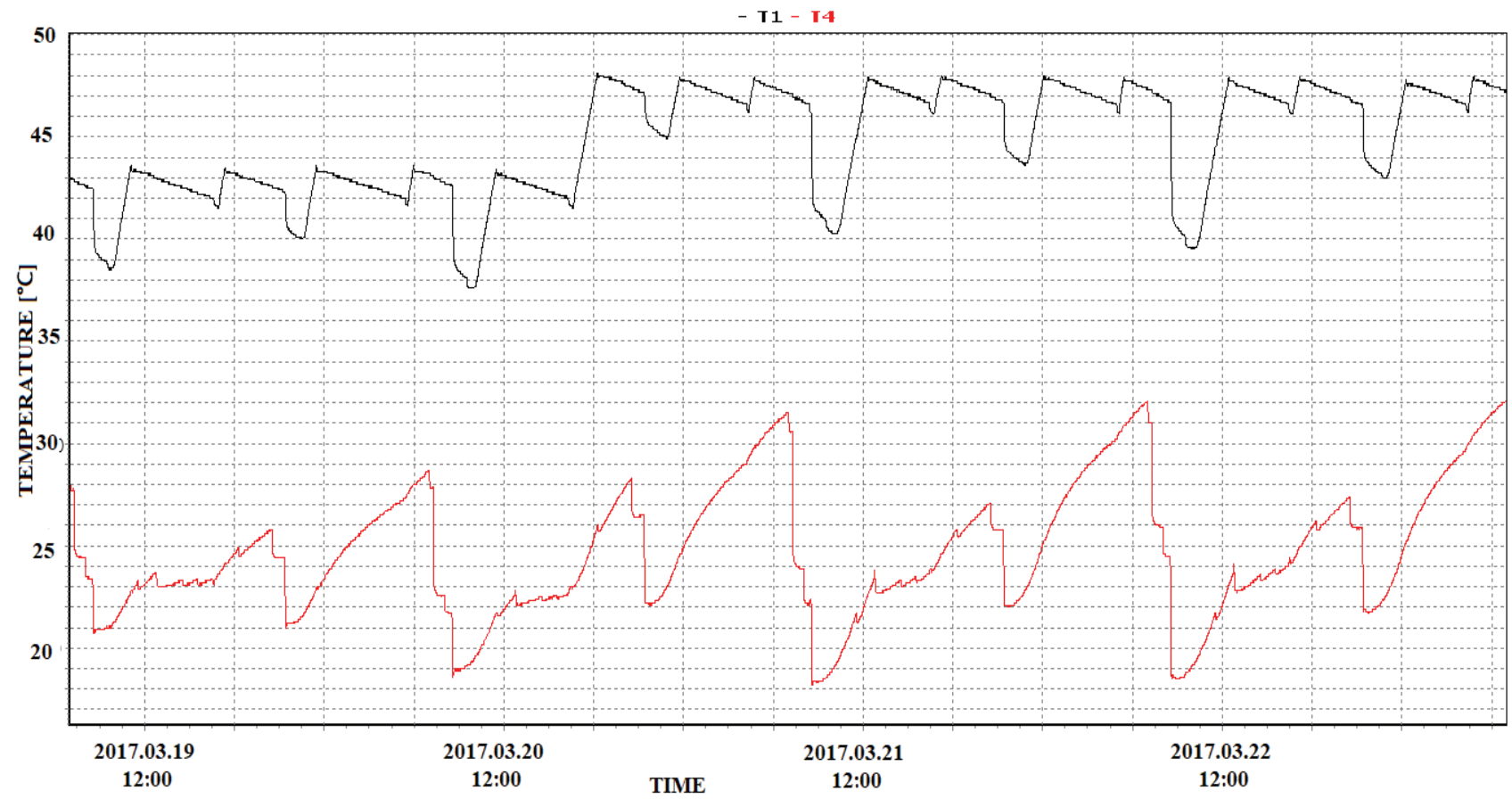

Fig. 4. Temperature chart in the water tank.

The heat flux delivered to water in the tank led to the decrease of the temperature behind condenser to a value in the range of $26-38^{\circ} \mathrm{C}$. The pressure of the steam dissipation from the refrigerant resulted in the decrease of its temperature to nearly $-1^{\circ} \mathrm{C}$ (in the initial phase) and $5^{\circ} \mathrm{C}$ (in the final phase).
Fig. 7 contains charts representing air relative humidity in the laboratory where the examined heat pump was located.

The air temperature in the room was in the range 16.4-19.5 $5^{\circ} \mathrm{C}$, whereas relative humidity of the air was in the range $17-40 \%$.

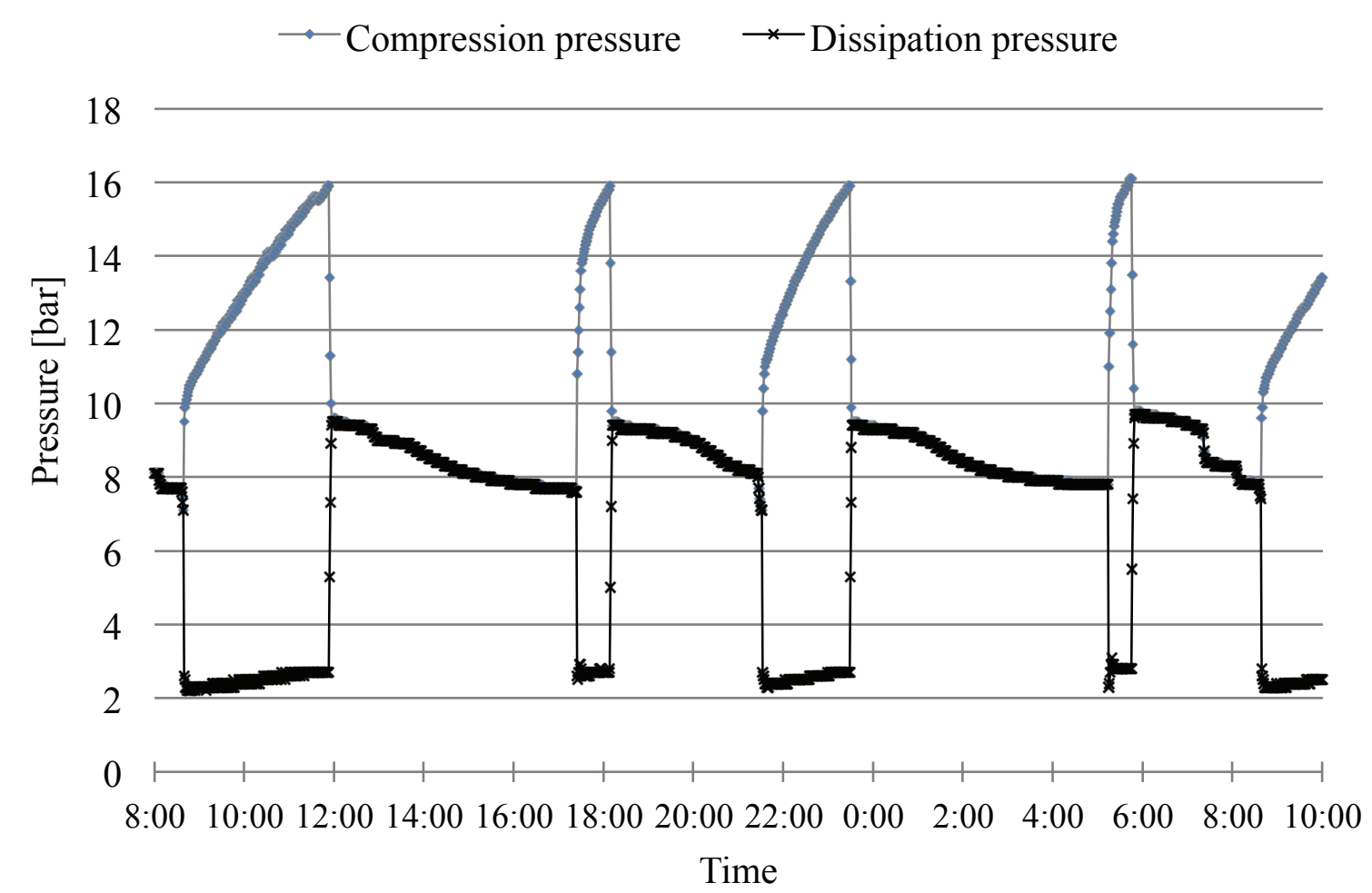

Fig. 5. Compression and dissipation pressure during the operation of the heat pump. 


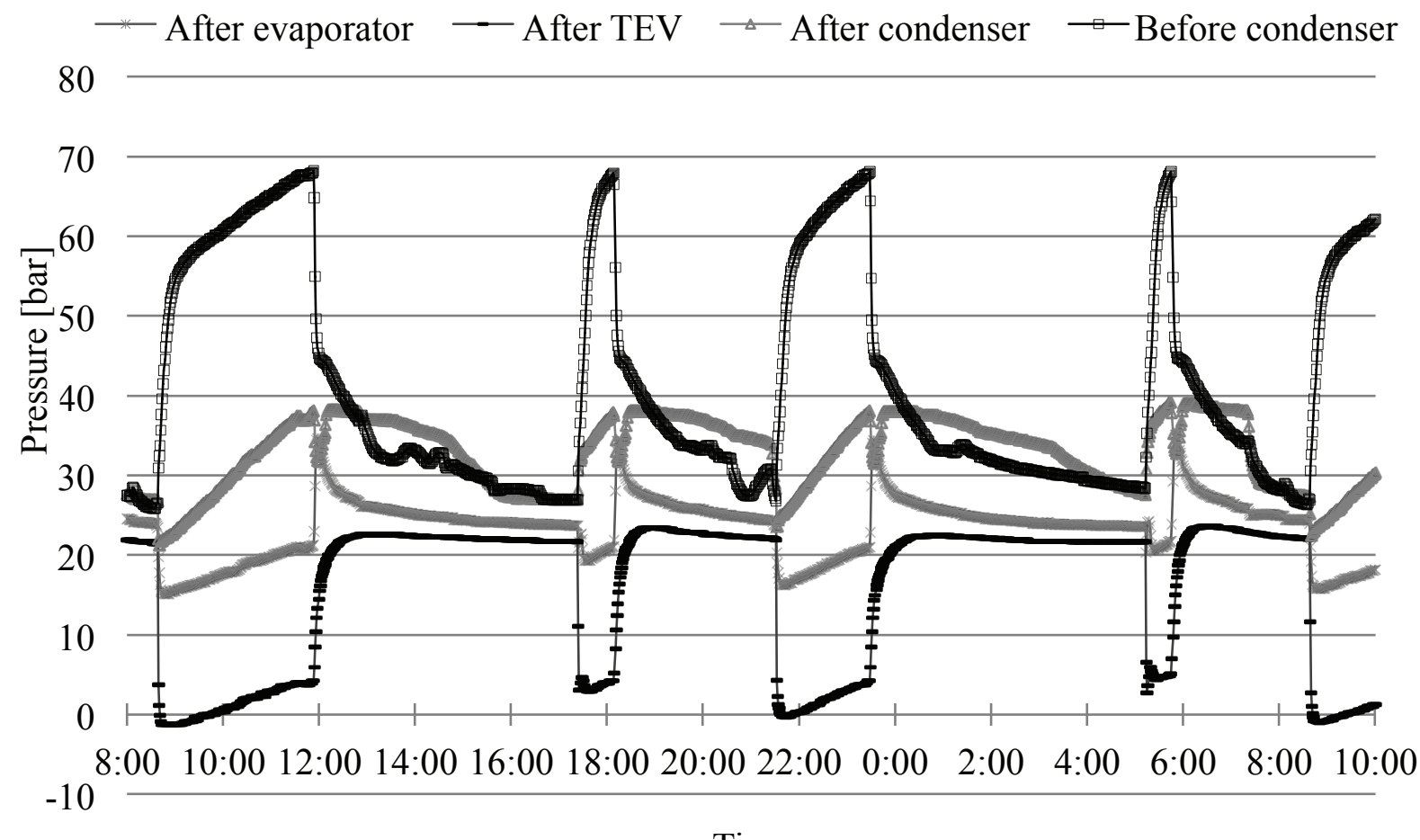

Time

Fig. 6. Temperatures of the refrigerant.

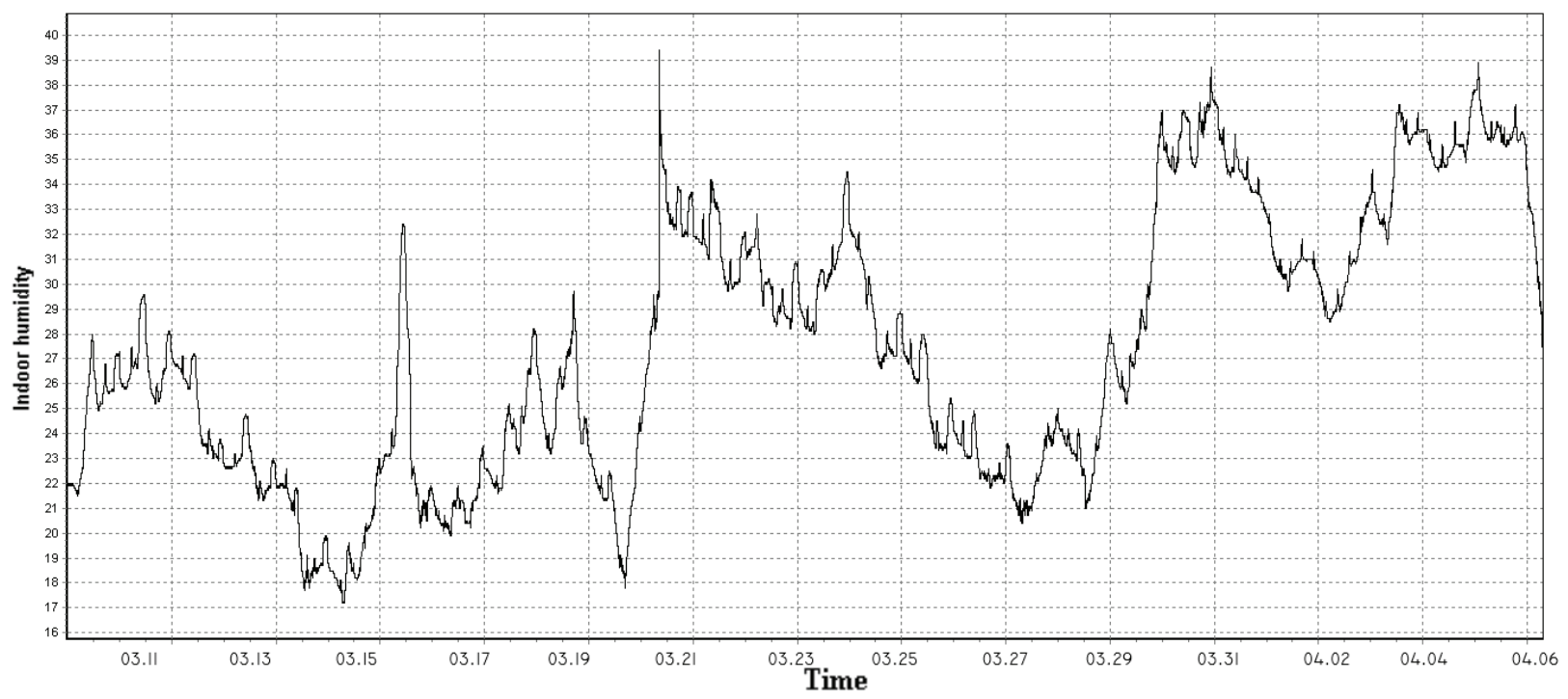

Fig. 7. Relative humidity in the laboratory.

Table 2 contains a summary of the results of the conducted research. On the basis of the analysis of the data, we can note that the heat pump produced 222.6 $\mathbf{k W h}$ of thermal energy in the form of domestic hot water throughout the duration of the test cycle.

By substituting the values of thermal energy and electricity consumption throughout the test duration into formula (1), we are able to determine the value of the coefficient of performance of the heat pump, which is equal to $\mathbf{2 . 4 3}$.

Fig. 8 illustrates the emission of pollutants into the environment, which resulted from the operation of the heat pump during the test
The calculations were performed by application of the standards in force and using software dedicated to performing ecological analysis- called Audytor EKO 1.0 .

The operation of the heat pump resulted in the generation of $0.142 \mathrm{~kg}$ sulphur dioxide by the emitter; the amount of nitrogen dioxide was smaller and equal to 0.103 kilograms.

The emission of carbon dioxide was nearly $88 \mathrm{~kg}$, and particulate matter $0.004 \mathrm{~kg}$.

Table 3 presents a comparison of the results of the conducted research compared with different sources of energy (gas boiler and boiler fired by the coal). 
Table 2. Test results.

\begin{tabular}{|c|c|c|}
\hline & Value & Unit \\
\hline Hot water use & 6.3 & $\mathrm{~m}^{3}$ \\
\hline $\begin{array}{c}\text { Thermal energy } \\
\text { generated by the heat } \\
\text { pump over the entire } \\
\text { test cycle }\end{array}$ & 222.6 & $\mathrm{kWh}$ \\
\hline $\begin{array}{c}\text { Electricity } \\
\text { consumption by the } \\
\text { heat pump over the } \\
\text { entire test }\end{array}$ & 91.7 & $\mathrm{kWh}$ \\
\hline COP & $\mathbf{2 . 4 3}$ & - \\
\hline \multicolumn{2}{|c|}{} \\
\hline
\end{tabular}

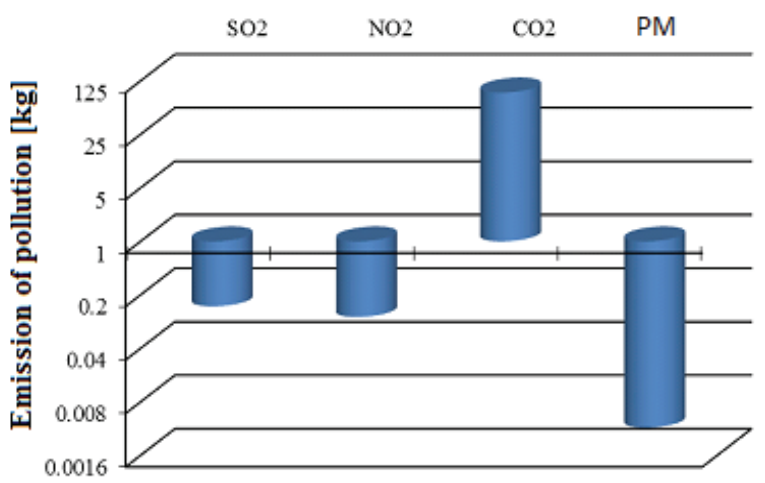

Fig. 8. Emission of pollutants in the analyzed period.

In this comparison the gas boiler with a closed combustion chamber is the most ecological source. The second place is the heat pump, the last is the boiler fired by the coal.

We can note at this point that the heat pump does not emit pollutants directly into the environment; yet, it is driven by electricity generated in Polish conditions by the power plants (emitter), which apply hard coal for the production of electricity.

Table 3. Comparison of emission different heat source.

\begin{tabular}{|c|c|c|c|}
\hline & $\begin{array}{c}\text { Air source } \\
\text { heat pump }\end{array}$ & Gas boiler & $\begin{array}{c}\text { Boiler } \\
\text { fired by } \\
\text { coal }\end{array}$ \\
\hline $\mathrm{SO}_{2}[\mathrm{~kg} / \mathrm{rok}]$ & 0.142 & 0.001 & 0.633 \\
\hline $\mathrm{NO}_{2}[\mathrm{~kg} / \mathrm{rok}]$ & 0.103 & 0.037 & 0.073 \\
\hline $\mathrm{CO}[\mathrm{kg} / \mathrm{rok}]$ & - & 0.007 & 1.484 \\
\hline $\mathrm{CO}_{2}[\mathrm{~kg} / \mathrm{rok}]$ & 87.96 & 49.23 & 61.01 \\
\hline $\mathrm{PM}[\mathrm{kg} / \mathrm{rok}]$ & 0.0037 & - & 0.2308 \\
\hline $\mathrm{Soot}[\mathrm{kg} / \mathrm{rok}]$ & - & - & 0.1154 \\
\hline $\mathrm{BAP}[\mathrm{kg} / \mathrm{rok}]$ & - & - & 0.0005 \\
\hline
\end{tabular}

The operation of the gas boiler resulted in the generation of $0.001 \mathrm{~kg}$ sulphur dioxide by the emitter; the amount of nitrogen dioxide was 0.037 kilograms. The emission of carbon dioxide was $49 \mathrm{~kg}$, and $\mathrm{CO}$ $0.007 \mathrm{~kg}$. The coal fired boiler was the most unecological source of the energy. The emission of the pollutants were: $\mathrm{SO}_{2}-0.633 \mathrm{~kg}, \mathrm{NO}_{2}-0.073 \mathrm{~kg}, \mathrm{CO}-$ $1.484 \mathrm{~kg}, \mathrm{CO}_{2}-61.01 \mathrm{~kg}, \mathrm{PM}-0.2308 \mathrm{~kg}$, Soot $0.1154 \mathrm{~kg}$ and BAP $-0.0005 \mathrm{~kg}$.

\section{Conclusions}

On the basis of the results of the study, it was possible to determine the value of the COP coefficient with regard to the tapping cycle of domestic hot water during a cycle that is similar to the recommended one contained in [11]. The following conclusions can be made from the study:

1) Heat pump was tested in accordance with the tapping cycle $L$ that is similar to the one found in [11].

2) The tested heat pump is characterized by a high value of the COP coefficient, whose value was 2.43 .

3) The operation of the equipment resulted in the generation of $0.142 \mathrm{~kg}$ of sulphur dioxide, 0.103 kilograms of nitrogen, $88 \mathrm{~kg}$ of dioxide carbon dioxide and $0.004 \mathrm{~kg}$ of particulate matter

4) Heat pumps employed for the production of domestic hot water offer an ideal alternative to the traditional systems of DHW production, as they are characterized by a considerable efficiency and relatively low cost associated with the investment and exploitation.

5) The heat pump is one of the most ecological friendly source of energy, because in the compression with another sources (e.g. gas or coal fired boiler). This device does not emit pollutants directly into the environment.

In addition, it is projected that heat pumps have the potential to replace a number of traditional technologies (e.g. solid fuel boilers and gas boilers) currently applied for production of domestic hot water.

\section{References}

1. A.S. Vieira, R.A. Stewart, C.D. Beal, Energy Build. 91, 148-162 (2015)

2. X. Liu, S. Lau, H. Li, Energy Build. 69, 1-13 (2014)

3. E. Ghisi, S. Gosch, R. Lamberts, Energy Policy 35, 4107-4120 (2007)

4. H. Singh, A. Muetze, P.C. Eames, Renewable Energy 35, 873-878 (2010)

5. L. Pérez-Lombard, J. Ortiz, C. Pout, Energy Build. 40, 394-398 (2008)

6. F. Alam, T. Theos, (Proceedings of the Fourth BSME-ASME International Conference on Thermal Engineering, 710-718, 2008)

7. M. Mironowicz, N. Szmolke, D. Skoruppa. Instal 10, $10-15$ (2014)

8. A. Gużda, N. Szmolke, J. Civil Eng. Env. Arch. 63, 4/16, 201-208 (2016)

9. O. Ibrahim, F. Fardoun, R. Younes, H. LouahliaGualous, Energy 64, 1102-1116 (2014)

10. J. Zhang, R.Z. Wang, J.Y. Wu, App. Therm. Eng. 27, 1029-1035 (2007)

11. PN-EN 16147:2011

12. P. Lachman, Instal Reporter, 01, 15-18 (2014) 